\title{
Finances and returns for robotic dairies ${ }^{1}$
}

\author{
J. A. Salfer, ${ }^{* 2}$ K. Minegishi, $†$ W. Lazarus, $\ddagger$ E. Berning, ${ }^{*}$ and M. I. Endres $\dagger$ \\ *University of Minnesota Extension, St. Cloud 56301 \\ †Department of Animal Science, and \\ ‡Department of Applied Economics, University of Minnesota, St. Paul 55108
}

\section{ABSTRACT}

Automatic milking systems (AMS) became commercially available in the early 1990s. These systems provide flexibility and improve the lifestyle of farmers installing them. Because of the larger capital cost per kilogram of milk produced, observational studies in Europe and simulation studies have shown AMS to be less profitable than milking parlor systems, although previous findings are somewhat mixed. Improved performance of newer generations of AMS, better facility design to accommodate cow behavior, and better management of these facilities have the potential to make AMS more profitable. Wage rates are also increasing and sourcing high-quality milking labor is challenging. We developed partial budget simulations to model profitability of AMS compared with parlor systems for 120-, 240-, and 1,500-cow farms. Both the 120-cow and 240-cow AMS were more profitable than the parlor systems. However, the 1,500-cow parlor system was more profitable than the AMS. Breakeven labor analysis of the 1,500-cow system showed that at a wage inflation rate of $1 \%$ and a $0.91 \mathrm{~kg} / \mathrm{d}$ lower milk production with the AMS system, the breakeven labor rate was $\$ 27.02 / \mathrm{h}$. If the farm is able to achieve similar milk production between the 2 systems and wage inflation averages $3 \%$ over the 30 -yr time horizon, the breakeven wage rate drops to $\$ 17.11 / \mathrm{h}$. The major management factors that influenced the net annual impact were changes in milking labor cost and milk production. Another significant factor affecting net annual impact was the economic life of the AMS. An economic life of $13 \mathrm{yr}$ or longer was required for an AMS to have a consistently positive net annual impact (depending on milk production per cow and labor cost). For every 227-kg increase in daily milk production per AMS, net annual income increased

Received September 8, 2016.

Accepted December 22, 2016.

${ }^{1}$ Presented as part of the Robotic Dairying: Adapting Farm and Business Management Symposium at the ADSA-ASAS Joint Annual Meeting, Salt Lake City, Utah, July 2016.

${ }^{2}$ Corresponding author: salfe001@umn.edu approximately $\$ 4,100$. Cost-effective ways to optimize milk per AMS are to minimize attaching and milking times and to optimize milking settings.

Key words: automatic milking system, economic analysis, net annual impact, economic simulation

\section{INTRODUCTION}

The first commercial automatic milking system (AMS) was installed in the Netherlands in 1992 (de Koning, 2010; Hogeveen and Steenveld, 2013). Since then, there has been consistent and rapid growth in their adoption, especially in Europe and more recently in North America. By some industry estimates, there are now over 35,000 AMS units on farms worldwide. In 2014, 5,180 units were sold, an increase of $8 \%$ over 2013 (Klimpel, 2016).

Currently, most operations using AMS are farms that rely mainly on family labor for milking. Surveys around the world show that the main motivating factors for installing AMS are related to flexibility and efficiency of labor, and the desire to minimize the need to hire non-family labor. A survey of 60 Dutch farmers who adopted AMS (Hogeveen et al., 2004) indicated that the top 2 reasons for installing the system were decreased heavy labor and labor flexibility with AMS. A survey of 53 farms in Minnesota and Wisconsin in 2012 (J. A. Salfer and M. I. Endres; unpublished results) found that the top 3 reasons for installing AMS, mentioned by $95 \%$ of farmers, were improved lifestyle, reduced hired labor, and the ability to grow without additional hired labor. Farmers are using the freed-up labor time to increase the milking herd, improve farm management, increase involvement in organizations or community, or for family time.

To date, economic analysis of AMS compared with conventional milking systems (CMS) is limited. Most simulation models have shown AMS to be less profitable than CMS (Dijkhuizen et al., 1997; Hyde and Engel, 2002; Rotz et al., 2003). Advances in AMS technology, better understanding of optimum AMS management, higher labor costs, and limited availability of labor may change these results. 


\section{Observational Studies in Europe}

Published studies with on-farm data are limited. Bijl et al. (2007) compared the economic performance of confinement Dutch dairy farms using AMS to their closely matched counterparts using CMS. They matched AMS and CMS farms based on the year of their milking system investment, total milk production, and ratio of milk output to land use. Thirty-one farms with each system were included. Although total milk production per farm and milk per cow were similar, farms using AMS had more cows and produced more milk per full-time employee (FTE) than did farms with CMS. Total labor was 29\% lower for AMS. Bijl et al. (2007) found no differences in total revenues or gross margins, but money available for rent, asset replacement, interest, labor, and profit was lower for AMS because of higher costs. However, when adjusted for labor, AMS farms had significantly higher total revenues (€206,378 vs. $€ 164,250)$ and higher gross margins ( $€ 163,056$ vs. $€ 127,939)$ and $€ 12,953$ greater costs for rent, depreciation, interest, and labor, and greater profit per FTE than CMS. Therefore, the amount of labor available could be a deciding factor when choosing the type of milking center to install. Other research has found that AMS requires 18 to $19 \%$ lower labor inputs (Gustafsson, 2004; Mathijs, 2004) or the same amount of labor (Wade et al., 2004; Bijl et al., 2007).

Steeneveld et al. (2012) compared the technical efficiency of 63 AMS and 337 CMS Dutch confinement dairies. Herd size, milk production per cow, land use, and total labor were similar between the systems. Farms with AMS had 27\% higher capital costs per 100 $\mathrm{kg}$ of milk than farms with CMS (€12.71 vs. €10.10; $P$ $<0.01)$.

Castro et al. (2012) evaluated AMS efficiency on 29 Spanish dairy farms. Farms averaged 52.7 cows/AMS, spent $51 \mathrm{~min} / \mathrm{d}$ fetching cows, and produced 10,410 $\mathrm{kg}$ of milk/cow per yr. The average visit to the AMS lasted $7.41 \mathrm{~min}$ with $10.67 \mathrm{~kg}$ of milk yield (MY). The yearly $\mathrm{MY} /$ robot was $550,000 \mathrm{~kg}$, but there was wide variation among farms. Five farms produced more than $700,000 \mathrm{~kg}$ of milk/robot per year. These 5 farms ranged from 59 to 68 cows/robot with a milking frequency of 2.4 to 2.6 times/d, at a cow occupation rate of up to $89.8 \%$. This is higher than the $494,000 \mathrm{~kg}$ of milk/robot that Bijl et al. (2007) found, and close to the estimated maximum capacity of 600,000 to $750,000 \mathrm{~kg}$ of milk/ robot per year (de Koning and Ouweltjes, 2000). Castro et al. (2012) calculated that, under ideal conditions, the average farm could milk an additional 16 cows/AMS if they could achieve a $94 \%$ cow occupation rate. This would result in $735,000 \mathrm{~kg}$ of milk/robot at a milking frequency of 2.48 times per cow/d. Using multiple lin- ear regression, they discovered that the number of cows per robot and milk flow rate could predict $87.7 \%$ of the variation in milk yield per robot.

\section{Labor Efficiency}

As previously mentioned, surveys indicate that the main reason farmers install AMS is because of labor, both flexibility and efficiency of labor, and the desire to minimize the need for hired labor. Although some researchers have reported labor savings on farms with AMS (Sonck, 1995; Mathijs, 2004), Steeneveld et al. (2012) found no difference in cows or MY per FTE. Minnesota Farm Business Management records (Finbin, 2016) from 2011 to 2015 showed that 52 AMS farms from the Upper Midwest averaged 1,000,673 $\mathrm{kg}$ of milk per FTE, whereas 603 similar-sized freestall barns with CMS averaged $699,836 \mathrm{~kg}$ of milk per FTE.

Another factor affecting the decision to install AMS is the future potential availability of milking labor. A recent survey of US dairy farmers indicated that $51 \%$ of all dairy labor was immigrant labor (Adcock et al., 2015). A 2010 survey of dairy farmers showed that expected future labor shortages increase the probability that farmers will exit the business (Susanto et al., 2010). The future availability of immigrant labor may decrease as this workforce becomes less agricultural or if tighter immigration laws pass in the United States. Migration from rural Mexico to US farms has decreased. As a result, US farms are required to source labor from more remote areas of Mexico or Central American countries. However, these areas have smaller populations so the potential to replace Mexican labor is limited (Taylor et al., 2012).

\section{AMS VERSUS CONVENTIONAL PARLOR SYSTEMS}

Literature on the economic simulations of AMS is scarce. In addition, the results of simulation models are inconsistent because they are heavily dependent on the assumptions used by researchers. Three simulation studies (Dijkhuizen et al., 1997; Hyde and Engel, 2002; Rotz et al., 2003) analyzed the relative economic performance of AMS compared with CMS in confinement housing. Two of these (Dijkhuizen et al., 1997; Hyde and Engel, 2002) used partial modeling to compare only the differences of implementing a new milking system. The third (Rotz et al., 2003) took a whole-farm simulation approach that included considerations for varying herd sizes, milking frequencies, and environmental impacts.

Dijkhuizen et al. (1997) calculated the breakeven level of investment in AMS below which AMS is more profitable than the parlor system. They modeled a 125-cow confinement operation, replacing an existing 
Table 1. Assumptions on automatic milking system simulations

\begin{tabular}{|c|c|c|c|}
\hline Variable & Dijkhuizen et al. (1997) & Hyde and Engel (2002) & Rotz et al. (2003) \\
\hline \multicolumn{4}{|l|}{ Baseline } \\
\hline Milk baseline production (kg/cow) & 7,000 & 8,165 & 10,900 \\
\hline Parlor: Investment cost $(\$)$ & 90,000 & 175,000 & 135,000 \\
\hline Interest rate $(\%)$ & 8 & 8 & 6 \\
\hline Inflation of milk and feed prices (\%) & 3.6 to 4.5 & 0 & 0 \\
\hline Labor wage rate $(\$ / \mathrm{h})$ & 7.60 & $\mathrm{NA}^{1}$ & 9.00 \\
\hline \multicolumn{4}{|l|}{ Annual production impact } \\
\hline Milk price $(\$ / 45.4 \mathrm{~kg})$ & 12.5 & 14.0 & 13.2 \\
\hline Robot: Increase in milk production (\%) & 12 & 12.7 & 5 \\
\hline Robot: Decrease in milk price (\%) & 0.7 & 1 & 2 \\
\hline Robot: Increase in feed cost $(\$)$ & 12,600 & 4,441 & 2,040 \\
\hline Robot: Labor savings $(\$)$ & 9,986 & 6,200 & 13,140 \\
\hline Insurance cost ( $\%$ of purchase price) & 0 & 0 & 0.5 \\
\hline Salvage value ( $\%$ of purchase price) & 5 & 5 & 30 \\
\hline
\end{tabular}

${ }^{1}$ Not available.

milking system with either an AMS or CMS. The AMS had reduced labor, increased milk production (due to increased milking frequency from twice-daily milking $(\mathbf{2} \times)$ to 3 -times-daily milking $(\mathbf{3} \times)$, increased maintenance cost, and increased cost of capital, compared with CMS. Table 1 shows the assumptions used in their simulation. They estimated the breakeven level to be about $\$ 175,000$. Overall, their results suggest that the relative benefit of AMS over CMS was unlikely to offset its cost even if assuming a wage rate of $\$ 20 / \mathrm{h}$ or a $16 \%$ increase in milk production with AMS.

Hyde and Engel (2002) used different assumptions (Table 1) and included stochastic considerations for key parameters in their model. For a 120-cow confinement operation, they found the breakeven level of AMS investment to be about $\$ 375,000$ (2 AMS units) with a standard deviation of $\$ 46,000$. Their sensitivity analysis suggested that the breakeven point would increase by $\$ 43,000$ with an increase in milking labor cost from $\$ 20,000$ to $\$ 40,000 / y r ;$ by $\$ 22,000$ with a $\$ 50,000$ increase in the cost of CMS; by $\$ 9,500$ with 1-yr decrease in the economic life of CMS; and by $\$ 32,000$ with 1-yr increase in the economic life of AMS. These are in contrast to the results of Dijkhuizen et al. (1997) and suggest that AMS would be more profitable than CMS as long as the additional facility cost and installation fee for AMS do not exceed the apparent net benefit of AMS investment over CMS.

Rotz et al. (2003) utilized a whole-farm simulation process based on a dairy forage system model. They simulated whole-farm confinement operations of AMS
$(2.5 \times$ and $3 \times$ milking $)$ and CMS $(2 \times$ and $3 \times$ milking $)$ for moderate and high milk production baselines $(8,600$ and $10,900 \mathrm{~kg} /$ cow per year, respectively). No increase in milk production was assumed for the AMS-2.5 $\times$ milking over CMS- $2 \times$ milking, whereas a $5 \%$ increase and a $12 \%$ increase were assumed for AMS- $3 \times$ and CMS- $3 \times$ milking scenarios, respectively. Both AMS and CMS were assumed to last for $10 \mathrm{yr}$. For the high production baseline, the results suggest that the net annual return per cow is $\$ 979$ and $\$ 1,063$ for CMS- $2 \times$ and CMS- $3 \times$ milking scenarios, and $\$ 622$ and $\$ 881$ for AMS-3× and AMS-2.8× milking scenarios. Their sensitivity analysis showed that the net return per cow under AMS would increase by approximately $\$ 100$ in response to a $10 \%$ increase in milk production, a $20 \%$ decline in the initial investment cost in AMS, or an increase in milking labor wage from $\$ 9 / \mathrm{h}$ to $\$ 18 / \mathrm{h}$. On the other hand, this net return would decrease by $\$ 100$ if the economic life of AMS were reduced from 10 to $7 \mathrm{yr}$. They concluded that AMS did not offer an economic benefit for most farm scenarios at that time.

We developed a partial budget tool to compare the financial impact of AMS versus CMS with farm sizes of 120,240, and 1,500 lactating cows under current economic conditions in the North Central region of the United States. Tables 2 and 3 show the assumptions we used; only the factors that differed between milking systems are included. All farms were confinementbased. Facilities and prices represent current industry standards. For example, the majority of 120-cow dairies primarily use family labor and milk $2 \times$ daily, so our 
Table 2. Assumptions across scenarios for our simulations

\begin{tabular}{|c|c|c|c|c|c|c|}
\hline Variable & \multicolumn{3}{|c|}{$\mathrm{CMS}^{1}$ (no. of cows in herd) } & \multicolumn{3}{|c|}{$\operatorname{AMS}^{1}$ (no. of cows in herd) } \\
\hline 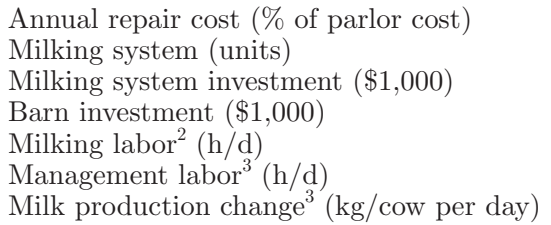 & $\begin{array}{r}3 \\
\text { D } 8 \\
384 \\
420 \\
8.5\end{array}$ & $\begin{array}{c}3 \\
\text { D8 } \\
512 \\
840 \\
16^{2}, 24^{2}\end{array}$ & $\begin{array}{r}3 \\
\mathrm{D} 24 \\
1,536 \\
5,250 \\
81.2\end{array}$ & $\begin{array}{c}5 \\
2 \text { AMS } \\
380 \\
1,060 \\
\quad 1.5 \\
+2.27\end{array}$ & $\begin{array}{l}5 \\
4 \text { AMS } \\
760 \\
1,640 \\
3.0 \\
-0.5 \\
+2.27^{4},-0.91^{5}\end{array}$ & $\begin{array}{l}5 \\
25 \text { AMS } \\
4,000 \\
9,750 \\
18.75 \\
-2 \\
-0.91\end{array}$ \\
\hline
\end{tabular}

${ }^{1} \mathrm{CMS}=$ conventional milking system or parlor; AMS = automatic milking system or robot; D8 = double 8 milking parlor, D24 = double 24 milking parlor.

${ }^{2}$ Milking labor for AMS includes cleaning stalls, scraping alleys/crossovers, and fetching cows. The 16 and 24 are the hours of milking labor associated with $2 \times$ milking and $3 \times$ milking for the CMS, respectively.

${ }^{3}$ Change compared with same herd size in CMS.

${ }^{4}$ For $2 \times$ milking.

${ }^{5}$ For $3 \times$ milking.

simulation used a double- 8 parlor that allows family members to milk in a short period. For the 1,500-cow dairy, hired labor is likely to be used for milking, so the parlor was sized to milk nearly around the clock to maximize capital and parlor efficiency. Barn investment per cow is considerably higher for AMS compared with CMS. The higher investment assumes that the barn is designed to minimize labor (i.e., automatic manure removal) and optimize cow access to the milking unit to maximize the benefit of AMS. We inflated labor costs at 1,2 , or $3 \%$ annually over the $30 \mathrm{yr}$ that we assume the dairy producer will continue to operate the dairy enterprise.

We assumed an increase of $2.27 \mathrm{~kg}$ of milk/cow per day for the AMS system compared with CMS with $2 \times$ milking because of increased milking frequency in the AMS, and a decrease of $0.91 \mathrm{~kg}$ of milk/cow per day for the AMS compared with CMS with $3 \times$ milking. There is a wide variation between herds in milk production response to AMS. de Koning (2010) found that herds

Table 3. Key assumptions similar across all herd sizes for our simulations

\begin{tabular}{lc}
\hline Variable & Value \\
\hline Milking labor rate $(\$ / \mathrm{h})$ & 16.00 \\
Management labor rate $(\$ / \mathrm{h})$ & 25.00 \\
Milk price $(\$ / \mathrm{kg})$ & 7.71 \\
Feed cost $(\$ / \mathrm{kg}$ of $\mathrm{DM})$ & 0.05 \\
Loan interest rate $(\%)$ & 5 \\
Equity interest rate $(\%)$ & 5 \\
Tax rate $(\%)$ & 40 \\
Weighted after-tax cost of capital $(\%)$ & 3 \\
Loan term on barn $(\mathrm{yr})$ & 20 \\
Loan term on milking system (yr) & 10 \\
Depreciation schedule & Accelerated \\
Insurance rate $(\%$ of new investment) & 0.5 \\
Useful life of the overall dairy operation $(\mathrm{yr})$ & 30 \\
\hline
\end{tabular}

milking with AMS had production increases of 5 to $10 \%$ compared with CMS herds milking $2 \times$, whereas AMS herds' production decreased 5 to $10 \%$ compared with milking $3 \times$ in a CMS.

We calculated the differences in projected annual net cash flows for AMS versus CMS over the 30 yr that the producer was assumed to continue operating the dairy enterprise. The cash flows consider milk revenues, feed, labor, maintenance, debt payments, and income taxes. Those net cash flows vary from year to year, making comparisons difficult. We "smoothed out" the year-toyear variability into a constant equivalent cash flow measure that accurately accounts for the time value of money, via a 2-step process. We first converted the projected annual cash flows to present values using a $3 \%$ weighted after-tax cost of capital (WACC) based on $5 \%$ rate before taxes, adjusted for a $40 \%$ tax rate, and summed them for a net present value (NPV) representing the whole 30 yr. Second, we used the Excel software PMT function (Microsoft Corp., Redmond, WA) to convert the NPV to a series of 30 constant annual payments (think "mortgage payments") at the $3 \%$ WACC, which we reported as net annual impact (NAI).

Our simulations showed mixed results. One source of uncertainty is how much labor rates might increase over the lifespan of the systems. Figures 1, 2, and 3 show how different labor inflation rates would affect the NAI if an AMS were compared with a CMS for different herd sizes. The 120- and 240-cow AMS systems had an NAI higher than the CMS. This is in contrast to older research with comparable herd sizes (Dijkhuizen et al., 1997; Hyde and Engel, 2002; Rotz et al., 2003). This is due in part to the higher milking labor costs, higher milk prices, and longer economic life of AMS in our simulation. For the 1,500-cow system, the CMS was more profitable than AMS under all comparisons. 


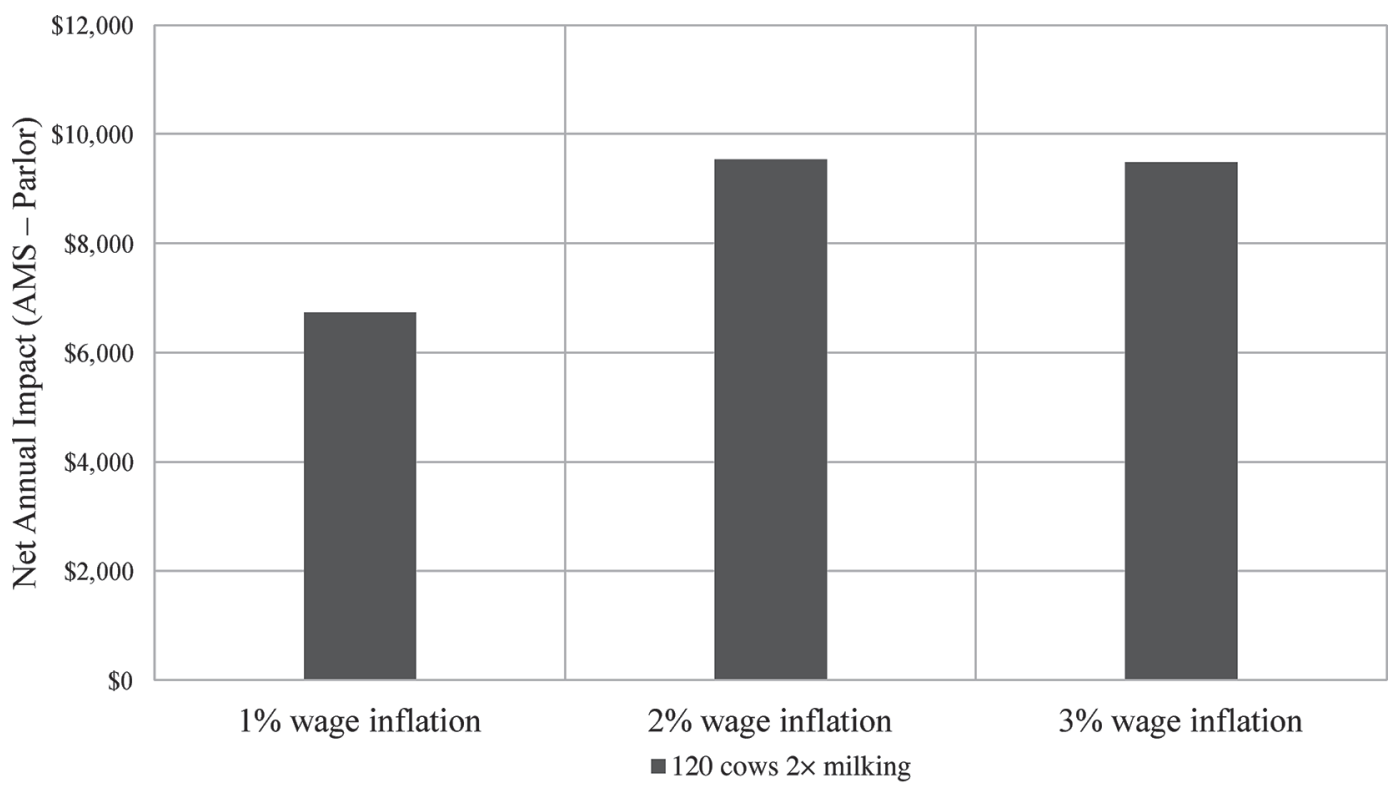

Figure 1. Net annual impact of 2 automatic milking system (or robot; AMS) units compared with double- 8 parlor.

Even using similar milk production levels between the 2 systems and $3 \%$ average annual wage inflation, the NAI was $\$ 12,665$ higher for the CMS. One reason for the differences between NAI with varying herd sizes is in the efficient use of milking system capital. Across all herd sizes, AMS was utilized at industry-standard capacity (60 cows per AMS unit). Milking system capital was more efficiently utilized with the 120- and 240-cow AMS systems. In the 120-cow CMS herd, the milking facility was only being utilized $4 \mathrm{~h} / \mathrm{d}$ or at $17 \%$ of maximum capacity. The 240-cow CMS $2 \times$ and $3 \times$ milking systems were only being used 8 and $12 \mathrm{~h} / \mathrm{d}$, respectively. For the 1,500-cow herd size, both the AMS and CMS were at near-maximum capacity. As discussed previously, milking labor might become more difficult to find in the future and this will influence the decision on what type of system producers will install to milk their cows.

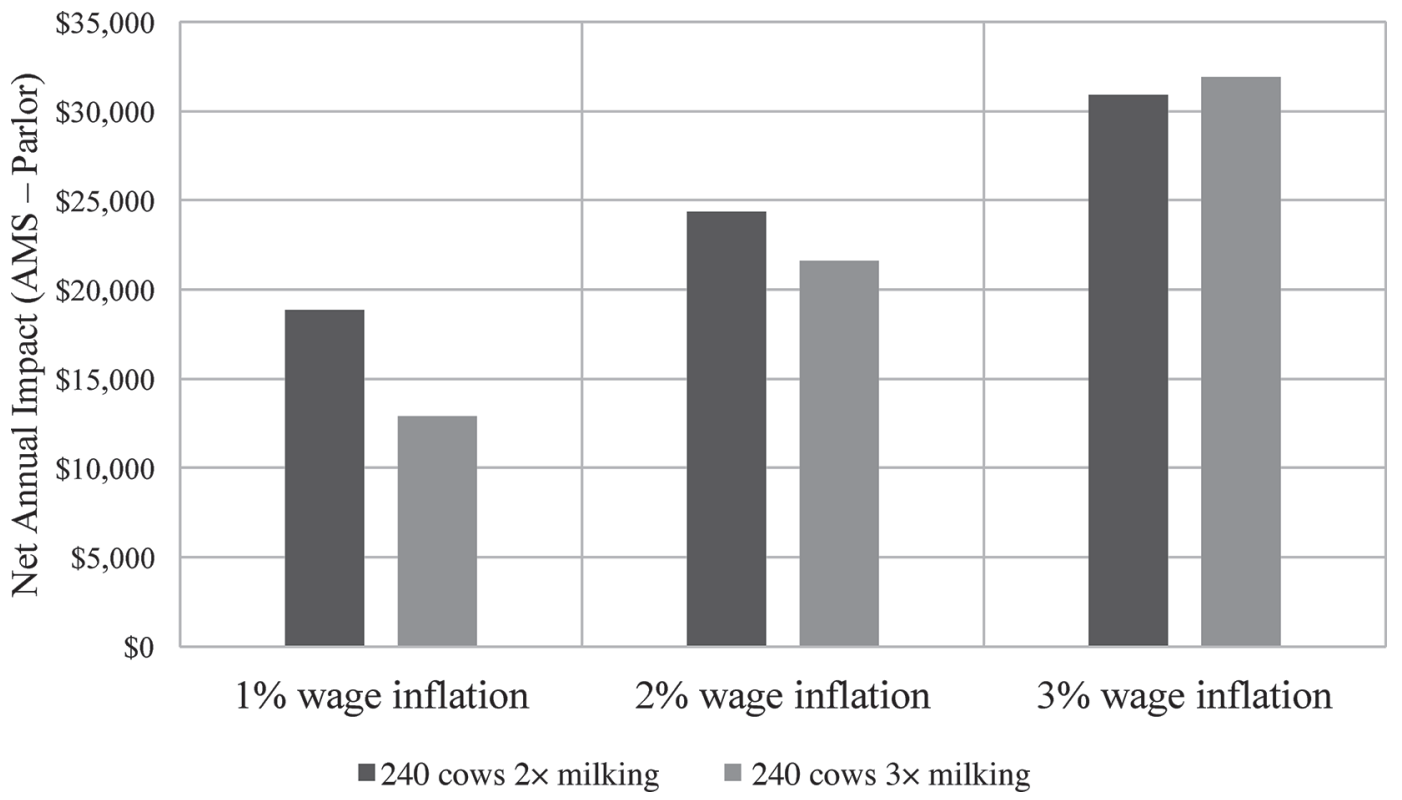

Figure 2. Net annual impact of 4 automatic milking system (or robot; AMS) units compared with double- 8 parlor. 


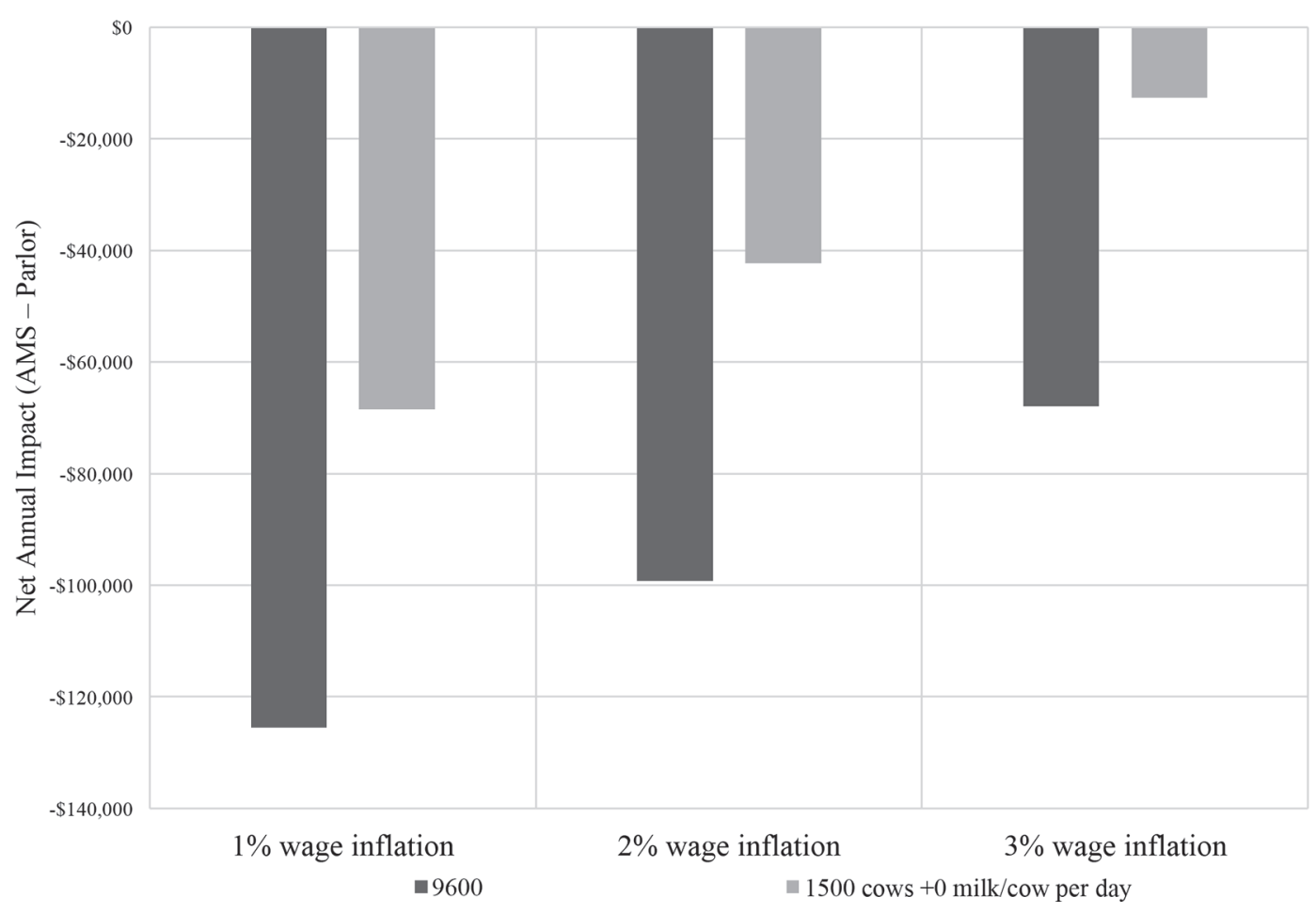

Figure 3. Net annual impact of 25 automatic milking system (or robot; AMS) units compared with double-24 parlor.

\section{Milk Production and Labor}

Two of the major factors that influence the profitability comparison of the 2 systems are the decreased milking labor costs and increased milk production from increased milking frequency with AMS. Milking labor costs have increased substantially over the past several years. According to the USDA (2016), average wages paid to livestock workers in the United States increased 3\% from 2014 to 2015 and 4\% from 2015 to 2016. We also assumed a decrease in management labor with the 240-cow and 1,500-cow AMS systems of 0.5 and $2 \mathrm{~h} / \mathrm{d}$, respectively. This decrease is due to the reduced requirement to recruit, hire, manage, train, and schedule milking labor. Research on the reduction in milking labor required with AMS is limited, but Bijl and colleagues (2007) found that AMS farms averaged 74 cows/FTE compared with 59 for CMS $(P<0.001)$, whereas Steeneveld et al. (2012) observed no statistical differences in labor cost (€10.30 vs. $€ 10.72 ; P=0.59$ ) of farms with AMS versus CMS.

In general, these simulations and on-farm studies show that AMS lag CMS in profitability. However, as mentioned previously, when Bijl et al. (2007) adjusted results to an FTE basis, total revenues ( $€ 206,378$ vs. $€ 164,250)$ and margin on dairy production (€148,582 vs. $€ 115,787)$ were higher for AMS than for CMS. They concluded that, by investing in AMS, farms are able to milk more cows and produce more milk without hiring additional labor. Among small farms, the total of labor hours is often similar. Low-value milking labor is often replaced by more economically valuable management labor (improving animal health, records analysis, reproductive performance, improving timeliness of cropping). Another factor not directly associated with amount of labor is the potential health benefit of decreased repetitive motion of milking. A 2012 survey (J. A. Salfer and M. I. Endres; unpublished results) showed that many producers installed AMS because of the long-term concerns about health of milkers' knees, backs, hips, and shoulders.

Some general observations are noted. First, assumptions have significant influence on simulation results. Costs and economic life of AMS and CMS have a large impact. Additionally, the milk production increase and labor decrease assumptions play a critical role in profitability projections. Large differences in assumptions lead to different results. An increased understanding of how AMS technology performs on farms will likely foster better understanding of economics of these milking systems. Second, the economic perspective and management style of the producer considered in the previous studies may be too narrow to account for real-world considerations for the AMS versus parlor decision. This 
is where the lifestyle improvement factor of AMS would play a major role. Future research may investigate who would likely benefit from choosing AMS over CMS as much as whether such investment in AMS makes economic sense.

\section{Breakeven Labor Rate}

Because the 1,500-cow AMS system scenario was less profitable, we wanted to determine the breakeven labor rate at which the AMS and CMS would have similar NAI (Figure 4). The breakeven labor rate is the current labor rate at which the AMS and CMS have the same NAI over the 30-yr time horizon. At a wage inflation rate of $1 \%$ and a $0.91 \mathrm{~kg} / \mathrm{d}$ lower milk production with the AMS system, the breakeven labor rate is $\$ 27.02 / \mathrm{h}$. If the farm is able to achieve similar milk production between the 2 systems and wage inflation averages $3 \%$ over the 30 -yr time horizon, the breakeven wage rate drops to $\$ 17.11 / \mathrm{h}$. Another consideration is the availability of high-quality labor.

\section{Breakeven Milk Production}

We also examined the milk production increase that the 1,500-cow AMS scenario needed to achieve a similar NAI as CMS (Figure 5). If the AMS can achieve $1.4 \mathrm{~kg}$ more milk/cow per day than CMS with $1 \%$ annual wage inflation, the NAI is \$16,993 higher for AMS. At $3 \%$ annual wage inflation rate and $30-y r$ economic life, the AMS is more profitable than the CMS, with increases of $0.45,0.91$, and $1.4 \mathrm{~kg} /$ cow per day. Recent research indicated that AMS did not achieve milk production similar to or higher than CMS milking $3 \times$. However, as AMS technology and management continue to improve, this could change. We continue to learn more about cow behavior in AMS that might lead to better facility design for optimum use of AMS. In AMS, cows are managed and milked in stable groups within pens. This eliminates the stress of regrouping, long walks to the parlor, stress in the holding area, and time away from feed. Cows have access to resources (feed, water, beds, milking) at all times. More individualized feeding of cows via the pelleted feed offered in the robot box can

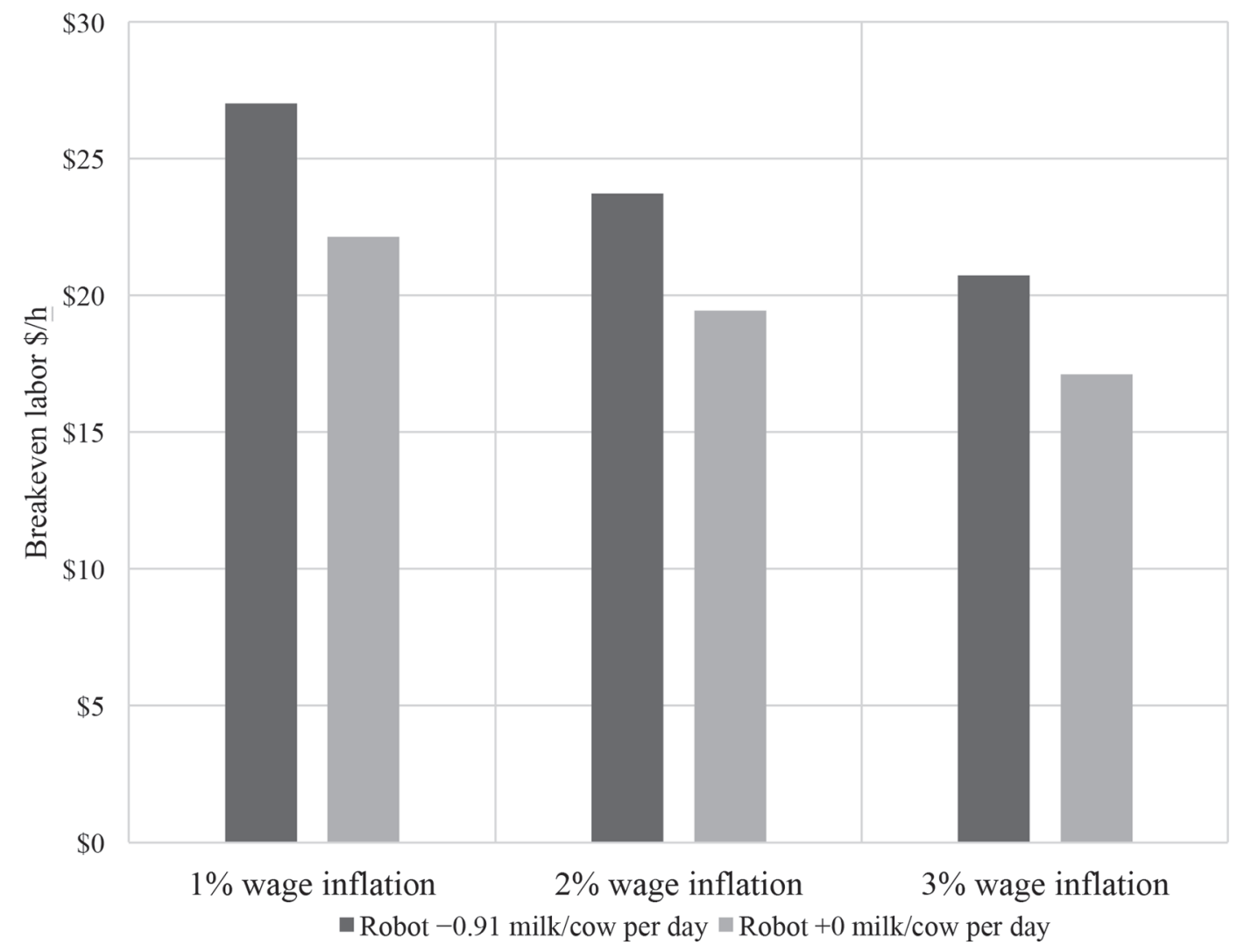

Figure 4. Breakeven labor rate of a 1,500-cow dairy with 25 automatic milking system (or robot; AMS) units compared with a double-24 parlor at 2 different milk production levels and wage inflation rates. The breakeven labor rate is the current labor rate at which the 25-unit AMS and double-24-parlor system have the same net annual impact over the 20-yr time horizon. 


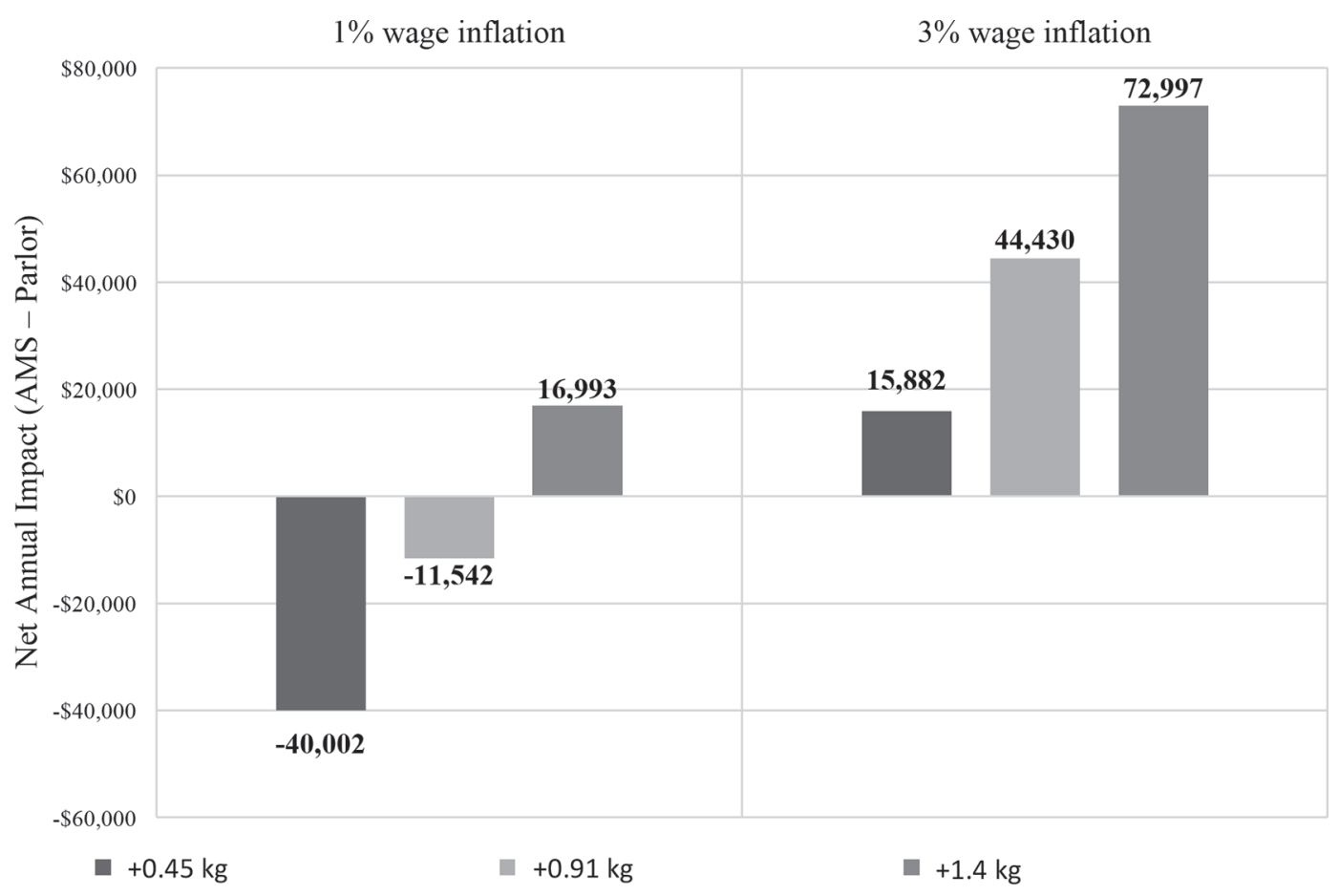

Figure 5. Net annual impact of a 1,500-cow dairy with 25 automatic milking system (or robot; AMS) units compared with a double-24 parlor at different milk production levels (in $\mathrm{kg}$ of milk per cow per day) and wage inflation rates.

help manage body condition and potentially increase milk per cow. If managers are able to optimize all of these parameters, it is likely possible to achieve higher milk production per cow in AMS systems.

\section{EFFECT OF AMS INSTALLATION}

We also examined the profitability of the dairy enterprise with an AMS milking system alone or in combination with a new high-technology facility. We created 2 different simulations. In the first, we considered investing in an AMS alone. This would be similar to retrofitting an AMS into an existing facility. The second scenario represented a comprehensive upgrade of the farm facility with a large investment financed over a long time horizon. This would be similar to a greenfield investment with new AMS and facility construction. Most parameters used for these calculations were equivalent to the previous case with few exceptions; we fixed wage inflation rate at $2.8 \%$ (i.e., the average growth rate of US agricultural labor wage in the past 10 yr) and varied milk yield, milking labor efficiency, and the economic lifespan of AMS across scenarios.

\section{AMS Alone}

We assumed a 180-cow system requiring $13.5 \mathrm{~h}$ of milking labor per day before the transition to AMS. The annual payment for the 3 AMS units is about
$\$ 63,000 / y r$ for 10 yr along with annual increase in insurance $(\$ 2,700)$ and maintenance $(\$ 9,000 /$ robot per year). In this simulation, the NAI represents the net return on investment with AMS per year, compared with a current milking system with no debt payments. Table 4 shows how NAI varies with different milking labor requirements for AMS and AMS lifespan with 3 scenarios for MY. Milking labor refers to activities such as identifying and gathering fetch cows, scraping stalls and alleys/crossovers, and keeping the AMS clean. Conceptually, this is labor similarly associated with the milking process in a CMS. A survey of AMS farms in Minnesota and Wisconsin found that well-designed (automatic manure removal, split entry pens), wellmanaged, free-flow AMS barns averaged about $45 \mathrm{~min}$ of milking type labor per AMS unit/d (M. I. Endres and J. A. Salfer; unpublished results). It is slightly lower with similar guided-flow barns. Using an AMS labor requirement of $45 \mathrm{~min} / \mathrm{d}$ per AMS, the benefit of labor savings starts at $\$ 65,700 / \mathrm{yr}$ and grows at $2.8 \%$ wage inflation rate. With no change in milk yield, the NAI is $-\$ 6,477, \$ 4,824$, and $\$ 10,725$ for AMS lifespans of 10,13 , and $15 \mathrm{yr}$, respectively. It approximately breaks even with an AMS useful life of 11 yr. Intuitively, a longer useful life spreads the capital investment over a longer period of time, increasing the benefits of the investment. At $60 \mathrm{~min} / \mathrm{d}$ per AMS labor requirement, the breakeven lifespan rises to $12 \mathrm{yr}$. 
Milk yield change has a large influence on NAI. A $0.9 \mathrm{~kg}$ per cow $/ \mathrm{d}$ increase in MY adds about $\$ 10,000$ to NAI. A decrease in MY of $0.9 \mathrm{~kg}$ per cow $/ \mathrm{d}$ affects the NAI negatively by about the same amount. Under the investment in AMS alone (with no additional facility construction), the dairy producer needs to reduce milking labor to approximately $45 \mathrm{~min} /$ robot, along with a small increase in MY, if the AMS system is going to have an improved NAI over an existing milking system. Robots must also last for at least 10 yr to break even.

\section{AMS with a New Barn}

It is probably best if the AMS is designed as part of a new, high-technology, low-labor-requirement facility to achieve maximum benefit. This facility may include various upgrades such as wider and more frequent crossovers to facilitate cow movement, automated manure removal, automated feed pushers, and a more temperature-controlled environment. These are costlier but contribute to increased ability of the cow to access the AMS unit and reduced labor. We assumed a new barn construction cost of $\$ 7,000$ per cow (excluding the cost of robots), which translates into an annual payment of about $\$ 101,000$ over 30 payment years for the 180-cow farm. The time horizon of this investment is the same as the useful life of the overall operation and the economic life of the new barn, which is assumed to be $30 \mathrm{yr}$.

Table 5 shows the results by projected milk yield increase and milking labor. This is compared with the previous MY and $13.5 \mathrm{~h}$ of milking labor/d. With a projected $3.6 \mathrm{~kg}$ per cow $/ \mathrm{d}$ increase in MY and a labor requirement of $2.25 \mathrm{~h} / \mathrm{d}$ (45 min/d per robot), the 15-yr- and 10-yr-lifespan cases indicate $\$ 2,220$ and $-\$ 27,974$ of NAI respectively. When seen as an integrated facility, robots and a new barn together must provide a substantial increase in MY and labor savings to recuperate the large investment. Depending on the desire to upgrade the AMS technology and the maximum time horizon, robots may be installed twice or 3 times during the $30-y r$ useful life of the overall operation.

\section{Economies of Scale}

The comparison between robots and parlors needs to account for likely differences in the economies of scale between the 2 milking systems. The unit cost of automation for the integrated AMS barns tend to decrease with scale, and large-scale CMS operations tend to run their parlors at full capacity for nearly $24 \mathrm{~h} / \mathrm{d}$, which effectively reduces the required parlor investment per cow. For instance, as the scale of operation changes from 180 to 1,500 cows, the barn cost may be reduced from $\$ 7,000$ to $\$ 6,000 /$ cow for the robot calculation, and the cost of parlors may decline from $\$ 3,000$ to $\$ 1,500 /$ cow for the parlor calculation. The annual impact of every $\$ 1,000$ in cost savings is approximately $\$ 51$ over the 30 yr overall operation useful life at the after-tax interest rate of $3 \%$.

\section{PROFITABILITY WITHIN AMS}

We also used our simulation model to investigate the effect of total daily MY/AMS unit on profitability within an AMS system. Net annual income increases approximately $\$ 4,100$ for every $227-\mathrm{kg}$ increase in daily milk production per AMS (Figure 6). Currently, some US farms are consistently achieving in excess of 2,700 $\mathrm{kg}$ of milk/AMS per day. Many factors can influence milk per AMS unit. Getting the correct cows milked at the correct frequency and interval has the potential to increase MY per AMS. Research has shown that

Table 4. Automatic milking system (or robot; AMS) alone: net annual impact by AMS economic life and milking labor ${ }^{1}$

\begin{tabular}{|c|c|c|c|c|c|c|c|}
\hline \multirow[b]{2}{*}{ Scenario } & \multirow{2}{*}{$\begin{array}{l}\text { Milking labor } \\
\text { (min/d per AMS) }\end{array}$} & \multicolumn{6}{|c|}{ AMS lifespan (yr) } \\
\hline & & 8 & 10 & 13 & 15 & 17 & 20 \\
\hline Milk yield increase of & 75 & $(\$ 14,153)$ & $(\$ 3,832)$ & $\$ 6,969$ & $\$ 12,528$ & $\$ 12,847$ & $\$ 13,747$ \\
\hline \multirow[t]{3}{*}{$0.9 \mathrm{~kg} / \mathrm{cow}$ per day } & 60 & $(\$ 10,954)$ & $(\$ 470)$ & $\$ 10,580$ & $\$ 16,311$ & $\$ 16,630$ & $\$ 17,529$ \\
\hline & 45 & $(\$ 7,754)$ & $\$ 2,891$ & $\$ 14,191$ & $\$ 20,093$ & $\$ 20,412$ & $\$ 21,312$ \\
\hline & 30 & $(\$ 4,555)$ & $\$ 6,253$ & $\$ 17,803$ & $\$ 23,875$ & $\$ 24,194$ & $\$ 25,094$ \\
\hline \multirow[t]{4}{*}{ No change in milk yield } & 75 & $(\$ 23,521)$ & $(\$ 13,199)$ & $(\$ 2,399)$ & $\$ 3,161$ & $\$ 3,480$ & $\$ 4,380$ \\
\hline & 60 & $(\$ 20,321)$ & $(\$ 9,838)$ & $\$ 1,212$ & $\$ 6,943$ & $\$ 7,262$ & $\$ 8,162$ \\
\hline & 45 & $(\$ 17,122)$ & $(\$ 6,477)$ & $\$ 4,824$ & $\$ 10,725$ & $\$ 11,044$ & $\$ 11,944$ \\
\hline & 30 & $(\$ 13,922)$ & $(\$ 3,115)$ & $\$ 8,435$ & $\$ 14,507$ & $\$ 14,827$ & $\$ 15,726$ \\
\hline Milk yield decrease of & 75 & $(\$ 32,888)$ & $(\$ 22,567)$ & $(\$ 11,767)$ & $(\$ 6,207)$ & $(\$ 5,888)$ & $(\$ 4,988)$ \\
\hline \multirow[t]{3}{*}{$0.9 \mathrm{~kg} /$ cow per day } & 60 & $(\$ 29,689)$ & $(\$ 19,206)$ & $(\$ 8,155)$ & $(\$ 2,425)$ & $(\$ 2,105)$ & $(\$ 1,206)$ \\
\hline & 45 & $(\$ 26,489)$ & $(\$ 15,844)$ & $(\$ 4,544)$ & $\$ 1,358$ & $\$ 1,677$ & $\$ 2,576$ \\
\hline & 30 & $(\$ 23,290)$ & $(\$ 12,483)$ & $(\$ 932)$ & $\$ 5,140$ & $\$ 5,459$ & $\$ 6,359$ \\
\hline
\end{tabular}

${ }^{1}$ Net annual impact compared with the status quo with $13.5 \mathrm{~h} / \mathrm{d}$ of milking labor (negative values in parentheses). 


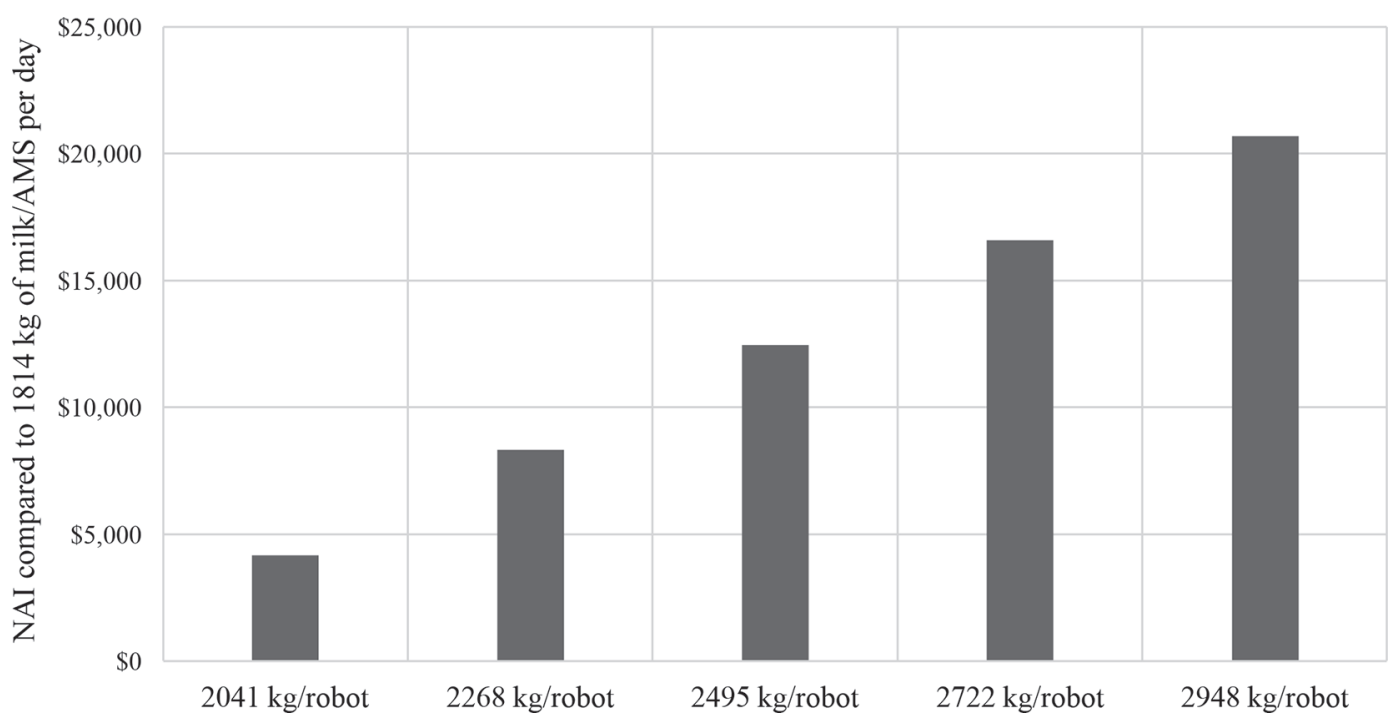

Figure 6. Net annual impact compared with 1,814 kg of milk per automatic milking system (or robot; AMS) units per day. Simulation using 240 cows, 4 AMS units, $2 \%$ annual wage inflation, and a 30 -yr time horizon.

increased milking frequency in early lactation increases milk production and decreases SCC, and this advantage extends beyond the period of increased milking frequency (Hale et al., 2003; Dahl et al., 2004; Eslamizad et al., 2010). Other studies (André et al., 2010; van der Tol, 2013) have shown that individual cows respond differently to varying milking intervals. Optimum milking permission settings and strategies that get the right cows milked at the correct times (earlylactation cows more frequently and later-lactation cows less frequently) will increase milk per AMS. A couple of key factors for high milk per AMS/d include high daily milk production and reduced box time per cow (Endres and Salfer, 2015). High production per cow results from increased visits by early-lactation cows and excellent transition cow programs that result in higher peak milk yields. Other factors include well-balanced diets (both partial mixed ration at the feed bunk and AMS box feed) and high reproductive efficiency. To minimize box time per cow, producers should select for cows that milk and attach fast, keep AMS equipment in top working condition, singe udders, and trim tail switches.

\section{CONCLUSIONS}

Most previous simulations and observational studies have shown that AMS is less profitable than CMS. However, labor wage rates and AMS technology have increased greatly in the past few years. It is unclear what will happen to wage rates in the future. An AMS will be more profitable under rapidly increasing wage rates than it will be under stable wage rates. Smaller farms want a more desirable lifestyle and larger farms have difficulty finding high-quality milking labor. In

Table 5. Automatic milking system (or robot; AMS) and a new barn: net annual impact by milk yield increase and milking labor ${ }^{1}$

\begin{tabular}{|c|c|c|c|c|c|c|c|}
\hline Scenario & $\begin{array}{l}\text { Milking labor } \\
\text { (min/d per AMS) }\end{array}$ & \multicolumn{6}{|c|}{ Milk yield increase (kg/cow per day) } \\
\hline \multirow[t]{3}{*}{ 15-yr AMS economic life ${ }^{2}$} & 60 & $(\$ 20,297)$ & $(\$ 10,930)$ & $(\$ 1,562)$ & $\$ 7,806$ & $\$ 17,173$ & $\$ 26,541$ \\
\hline & 45 & $(\$ 16,515)$ & $(\$ 7,147)$ & $\$ 2,220$ & $\$ 11,588$ & $\$ 20,955$ & $\$ 30,323$ \\
\hline & 30 & $(\$ 12,733)$ & $(\$ 3,365)$ & $\$ 6,002$ & $\$ 15,370$ & $\$ 24,738$ & $\$ 34,105$ \\
\hline 30-yr time horizon; & 75 & $(\$ 53,432)$ & $(\$ 44,064)$ & $(\$ 34,696)$ & $(\$ 25,329)$ & $(\$ 15,961)$ & $(\$ 6,594)$ \\
\hline 10-yr AMS economic life ${ }^{3}$ & 30 & $(\$ 43,347)$ & $(\$ 33,980)$ & $(\$ 24,612)$ & $(\$ 15,244)$ & $(\$ 5,877)$ & $\$ 3,491$ \\
\hline
\end{tabular}

${ }^{1}$ Net annual impact compared with the status quo with $13.5 \mathrm{~h} / \mathrm{d}$ milking labor. The milking labor of 3.75, 3.00, 2.25, and 1.50 h/d equals 75 , 60, 45, and 30 min per AMS/d (negative values in parentheses).

${ }^{2} \mathrm{AMS}$ is replaced twice over the 30 -yr time horizon.

${ }^{3} \mathrm{AMS}$ is replaced 3 times over the 30 -yr time horizon. 
addition, our understanding of AMS facility design, feeding, and management will continue to improve, resulting in decreased labor requirement and higher milk production with AMS. The main management factors affecting whether AMS is more profitable than CMS are increased milk production per cow and labor savings. Another major factor is years of economically useful life. To maximize profit, AMS users should optimize milk production per robot. To compare the relative return of AMS versus CMS, producers need to understand how their management style and preferences and economies of scale and future wage inflation affect potential future net income.

\section{ACKNOWLEDGMENTS}

The online tool was funded by USDA-NIFA award number 2015-49200-24226.

\section{REFERENCES}

Adcock, F., D. Anderson, and P. Rossen. 2015. The economic impacts of immigrant labor on U.S. dairy farms. Center for North American Studies at Texas A\&M University, College Station, TX.

André, G., P. B. M. Berentsen, B. Engel, C. J. A. M. de Koning, and A. G. J. M. Oude Lansink. 2010. Increasing the revenues from automatic milking by using individual variation in milking characteristics. J. Dairy Sci. 93:942-953.

Bijl, R., S. R. Kooistra, and H. Hogeveen. 2007. The profitability of automatic milking on Dutch dairy farms. J. Dairy Sci. 90:239-248.

Castro, A., J. M. Pereira, C. Amiama, and J. Bueno. 2012. Estimating efficiency in automatic milking systems. J. Dairy Sci. 95:929-936.

Dahl, G. E., R. L. Wallace, R. D. Shanks, and D. Lueking. 2004. Effects of frequent milking in early lactation on milk yield and udder health. J. Dairy Sci. 87:882-885.

de Koning, C. J. A. M., and W. Ouweltjes. 2000. Maximizing the milking capacity of an automatic milking system. Pages 438-46 in Automatic Milking: A Better Understanding. A. Meijering, $H$. Hogeveen, and C. J. A. M. de Koning, ed. Wageningen Academic Publishers, Wageningen, the Netherlands.

de Koning, K. 2010. Automatic milking - Common practice on dairy farms. Pages V59-V63 in Proc. Second North Am. Conf. Robotic Milking, Toronto, Canada. Precision Dairy Operators, Elora, Canada.

Dijkhuizen, A. A., R. B. M. Huirne, S. B. Harsh, and R. W. Gardner. 1997. Economics of robot application. Comput. Electron. Agric. $17: 111-121$.

Endres, M. I., and J. A. Salfer. 2015. An evaluation of automated milking systems in the Midwest United States. J. Dairy Sci. 98(Suppl. 2):114. (Abstr.)

Eslamizad, M., M. Dehghan-Banadaky, K. Rezayazdi, and M. MoradiShahrbabak. 2010. Effects of 6 times daily milking during early versus full lactation of Holstein cows on milk production and blood metabolites. J. Dairy Sci. 93:4054-4061.

Finbin. 2016. Livestock: Dairy summary report. Center for Farm Financial Management, University of Minnesota. Accessed Aug. 8, 2016. https://finbin.umn.edu.
Gustafsson, M. 2004. Working time studies in farms with conventional and automatic milking system. Pages 488-488 in Automatic Milking: A Better Understanding. A. Meijering, H. Hogeveen, and C. J. A. M. de Koning, ed. Wageningen Academic Publishers, Wageningen, the Netherlands.

Hale, S. A., A. V. Capuco, and R. A. Erdman. 2003. Milk yield and mammary growth effects due to increased milking frequency during early lactation. J. Dairy Sci. 86:2061-2071.

Hogeveen, H., K. Heemskerk, and E. Mathijs. 2004. Motivations of Dutch farmers to invest in an automatic milking system or a conventional milking parlour. Pages 56-61 in Automatic Milking: A Better Understanding. A. Meijering, H. Hogeveen, and C. J. A. M. de Koning, ed. Wageningen Academic Publishers, Wageningen, the Netherlands.

Hogeveen, H., and W. Steenveld. 2013. Integrating it all: Making it work and pay at the farm. Pages 113-121 in Proc. Precision Dairy 2013, Rochester, MN. University of Minnesota, St. Paul. Accessed Jan. 27, 2017. https://www.ansci.umn.edu/sites/ansci.umn.edu/ files/2013_precision_dairy_proceedings.pdf.

Hyde, J., and P. Engel. 2002. Investing in a robotic milking system: A Monte Carlo simulation analysis. J. Dairy Sci. 85:2207-2214.

Klimpel, S. 2016. Precision dairy technology on the way - and how it can really break through. Pages 89-93 in Proc. Precision Dairy Farming 2016. Wageningen Academic Publishers, Wageningen, the Netherlands.

Mathijs, E. 2004. Socio-economic aspects of automatic milking. Pages 46-55 in Automatic Milking: A better understanding. A. Meijering, H. Hogeveen, and C. J. A. M. de Koning, ed. Wageningen Academic Publishers, Wageningen, the Netherlands.

Rotz, C. A., C. U. Coiner, and K. J. Soder. 2003. Automatic milking systems, farm size, and milk production. J. Dairy Sci. 86:41674177.

Sonck, B. R. 1995. Labor research on automatic milking with a human-controlled cow traffic. Neth. J. Agric. Sci. 43:261-285.

Steeneveld, W., L. W. Tauer, H. Hogeveen, and A. G. J. M. Oude Lansink. 2012. Comparing technical efficiency of farms with an automatic milking system and a conventional milking system. J. Dairy Sci. 95:7391-7398.

Susanto, D., C. P. Rosson, D. P. Anderson, and F. J. Adcock. 2010. Immigration policy, foreign agricultural labor, and exit intentions in the United States dairy industry. J. Dairy Sci. 93:1774-1781.

Taylor, J. E., S. R. Boucher, A. Smith, P. L. Fletcher, and A. YunezNaude. 2012. Immigration and the US farm labour supply. Migration Lett. 9:87-99.

USDA-NASS (National Agricultural Statistics Service). 2016. Farm Labor. May 16. USDA, Washington, DC. Accessed Jan. 27, 2017. http://usda.mannlib.cornell.edu/usda/nass/ FarmLabo//2010s/2016/FarmLabo-05-19-2016.pdf.

van der Tol, R., P. Kool, and B. Smink. 2013. Increased AMS performance by optimized individual milk intervals. Pages $37-38$ in Proc. Precision Dairy 2013, Rochester, MN. University of Minnesota, St. Paul. Accessed Jan. 27, 2017. https://www.ansci.umn.edu/sites/ ansci.umn.edu/files/2013_precision_dairy_proceedings.pdf.

Wade, K. M., M. A. P. M. van Asseldonk, P. B. M. Berentsen, W. Ouweltjes, and H. Hogeveen. 2004. Economic efficiency of automatic milking systems with specific emphasis on increases in milk production, Pages 62-67 in Automatic Milking: A Better Understanding. A. Meijering, H. Hogeveen, and C. J. A. M. de Koning, ed. Wageningen Academic Publishers, Wageningen, the Netherlands. 